\title{
Dietary intakes of Gambian women: impact of the nutrition transition
}

\author{
S.E. Dalzell ${ }^{1}$, L.M.A. Jarjou ${ }^{2}$, A. Prentice ${ }^{1,2}$, K. Ward ${ }^{1}$ and G.R. Goldberg ${ }^{1,2}$ \\ ${ }^{1}$ Medical Research Council Elsie Widdowson Laboratory, Cambridge CB1 9NL, UK and \\ ${ }^{2}$ Medical Research Council Unit The Gambia, The Gambia
}

The Gambia is a West African country in nutritional, demographic and epidemiological transition. The climate is sub-tropical with both wet and dry seasons impacting food availability and nutritional status. The nutrition transition is associated with shifts from traditional to Western patterns of food consumption and physical activity; i.e. reduced intakes of fruit and vegetables, increased consumption of oil and sugar, and a more sedentary lifestyle.

Nutrition research in the rural district of Kiang West in The Gambia has enabled characterisation of food and nutrient intakes of a rural population. Most people are subsistence farmers, spending significant time outdoors exposed to UVB sunshine. The diet consists of cereals, predominantly rice, combined with sauces, typically composed of groundnuts or leaves, depending on the season. Due to limited consumption of animal products e.g. dairy and meat, intakes of important minerals are low, particularly calcium. Despite the habitually low calcium, reported incidence of fragility fracture is low ${ }^{(1)}$.

The aim of this study was to investigate whether migrating to an urban environment impacted dietary intakes of bone forming minerals. This research formed part of a larger study investigating the impact of nutrition transition on bone health in Gambian women living in rural and urban areas of The Gambia. As part of this study we conducted a 2 day prospective weighed diet record. Data were collected for two groups of pre-menopausal Gambian women: urban migrant $(n=59)$ and rural $(n=75)$. Both groups spent their formative years in the same rural setting, selected urban women were known to have migrated when aged $\geq 16$ years. Food and nutrient intakes were calculated using Gambian food composition tables and Diet in Nutrients out (DINO), a programme which enables both coding of dietary data and export of nutrient intakes ${ }^{(2)}$.

Mean age and height of rural and urban groups were not significantly different $(p>0.05)$. Urban migrant women were significantly heavier: urban $69.2 \pm 15.6 \mathrm{~kg}$ and rural $60.5 \pm 12.2 \mathrm{~kg}(\mathrm{p}<0.01)$. There were no significant differences in energy intake or macronutrient composition of the diet; approximately $65 \%$ of energy came from carbohydrates. Calcium intakes were low in both groups, urban migrant $294 \mathrm{mg} / \mathrm{d}$ (IQR: 235 to 385) and rural $305 \mathrm{mg} / \mathrm{d}$ (IQR: 222 to 420). Urban women had significantly lower intakes of potassium, magnesium and dietary fibre $(\mathrm{p}<0.01)$, related to lower consumption of fruit, green leafy vegetables and groundnuts. These differences reflect the early stages of the nutrition transition; implications for bone health and other non-communicable diseases requires further research.

\begin{tabular}{|c|c|c|c|c|c|}
\hline & \multicolumn{2}{|l|}{ Rural* } & \multicolumn{2}{|c|}{ Urban Migrant* } & \multirow[b]{2}{*}{$p$-value } \\
\hline & Mean $^{\mathrm{a}}$ & $\mathrm{SD}^{\mathrm{b}}$ & Mean $^{\mathrm{a}}$ & $\mathrm{SD}^{\mathrm{b}}$ & \\
\hline Energy kJ/d & 7153 & 2012 & 7385 & 2199 & 0.5 \\
\hline Fat g/d & $40 \cdot 1$ & $20 \cdot 3$ & $45 \cdot 2$ & $17 \cdot 1$ & $0 \cdot 1$ \\
\hline Carbohydrate g/d & $307 \cdot 3$ & $83 \cdot 1$ & $305 \cdot 0$ & $94 \cdot 2$ & 0.9 \\
\hline Protein g/d & $51 \cdot 4$ & 14.9 & $55 \cdot 4$ & $18 \cdot 4$ & 0.2 \\
\hline Phosphorus mg/d & 707 & 211 & 697 & 225 & 0.8 \\
\hline Calcium mg/d ${ }^{\text {ab }}$ & 305 & 222,420 & 294 & 235,385 & $0 \cdot 5$ \\
\hline Potassium mg/d & 2154 & 693 & 1823 & 518 & 0.002 \\
\hline Magnesium mg/d & 432 & 143 & 364 & 116 & 0.003 \\
\hline
\end{tabular}

\section{Acknowledgements}

Supported by the UK Medical Research Council (MRC) under programmes U105960371 and U123261351. This research is jointly funded by the $\mathrm{MRC}$ and the Department for International Development (DFID) under the MRC/DFID Concordat agreement. SD is in receipt of an MRC $\mathrm{PhD}$ studentship.

1. Aspray TJ, Prentice A, Cole TJ et al. (1996) J Bone Miner Res 11, 1019-1025.

2. Fitt E, Cole D, Ziauddeen N et al. (2015) Public Health Nutrition 18, 234-241. 